\title{
Assessment of the impact of latrine utilization on diarrhoeal diseases in the rural community of Hulet Ejju Enessie Woreda, East Gojjam Zone, Amhara Region
}

\author{
Andualem Anteneh ${ }^{1}$, Abera Kumie ${ }^{2}$
}

\begin{abstract}
Background: The construction of latrine is a relatively simple technology that is used to prevent the spread of infectious diseases. While household access is important, community sanitation coverage is even more important to improve health through the regular use of well-maintained sanitation facilities.

Objective: Assessing the impact of latrine utilization on diarrhoeal diseases in the rural community in the district of Hulet Ejju Enessie Woreda, East Gojam.

Method: A community based descriptive cross-sectional study was conducted in a randomly selected 824 households that had $90 \%$ latrine coverage at the time data collection in 2006. A structured and pre-tested questionnaire complemented with observation was used to collect data. The study area is found in one of the districts of East Gojjam where the health services extension program was actively underway. Trained data collectors and supervisors were involved in the study. Data entry and cleaning was done using EPI INFO 6.04d, while SPSS version 11 was used for data analysis.

Results: Most (61\%) households with traditional pit latrines had latrine utilization. In a bivaraite analysis, the extent of latrine utilization was significantly associated with presence of primary or secondary school children in the house [AOR: 1.47, 95\% CI: (1.04-2.06)], perceived reasons for latrine construction [AOR: 2.89, 95\% CI: (1.24-6.72)] and learning from neighborhoods [AOR: 10.07, 95\% CI: (1.97-51.56)], ecology of 'Kolla' [AOR: 0.47, 95\% CI: (0.29-0.74) and 'Woyna-Dega' [AOR: 0.55, 95\% CI: $(0.38-0.81)$, and owning latrines for $\geq 2$ years [AOR: $2.13,95 \%$ CI: (1.572.89)]. The occurrence of childhood diarrhoea was not statistically associated with the extent of latrine utilization [AOR: $0.63,95 \%$ CI: $(0.22-1.81)$ ]; however, only owning latrines for $\geq 2$ years remained significant in a multivariate analysis [AOR: $0.28,95 \%$ CI: (0.12-0.66)].

Conclusion: Utilization of latrine facilities was common among the majority of households. The duration of having latrines had impacted the occurrence of childhood diarrhea. [Ethiop. J. Health Dev. 2010;24(2);110-118]
\end{abstract}

\section{Introduction}

Over 50 different infections are potentially transmitted from an infected person to a healthy one by various routes involving excreta (2). The use of sanitation facilities is known to interrupt the transmission of faecooral related disease (2-4). The construction of traditional pit latrine is relatively a simple technology that is available to control the spread of diarrhea that is prevalent in developing nations (5). However, 2.4 billion people, $40 \%$ of the total world population, lack improved sanitation and $80 \%$ of these people live in rural areas of the developing world (5-8). In the WHO African Region, a total of 631 million people, $(40 \%)$, had no access to any kind of improved sanitation facilities in 2000 (9). This figure is about the same (36\%) in 2002 for Sub-Saharan African nations (10). A very recent publication of WHO/UNICEF indicated Africa is lagging much to attain MDG goals in sanitation, that aims to achieve improving a coverage of $38 \%$ (in 2006) to a level of $66 \%$ (in 2015) (11).

In Ethiopia, according to Demographic and Health Survey 2005 , about $62 \%$ of the households $(12 \%$ in Urban and $70 \%$ in Rural) had no access to any type of latrine facilities (12). The same data source indicated the proportion of households with private improved sanitation was only $6.8 \%$. This is highly unacceptable given the national prevalence of diarrhea diseases, $18 \%$, among under-five children (12) whose mortality is one of the decisive indicators in the MDG goals (13). Overall child mortality could be reduced by $55 \%$ with the provision of safe water, sanitation and hygiene (14). The prevalence of diarrhea in Ethiopia has wider variation, from $11 \%$ to $38 \%(15-17)$, that mainly depends on season, ecology, and water and sanitation coverage.

Health improvement comes from the proper use of sanitation facilities, not simply because of their merely physical presence (4). The proper use of latrines can reduce the risk of diarrhea to almost the same extent as improved water supplies, but generally the greatest benefit occurs when improvements in sanitation and water supply are combined and education is given on hygienic practices $(14,18-20)$. However, there is another view that the efficiency of controlling diarrhea could depend on a single intervention and not as a result of combined effort (21-23).

\footnotetext{
TEast Gojjam Zonal Health Department, Amahara Regional Health Bureau, P.O. Box: 495, Tel: +251911865239, +252582201715, Fax: +251587711933, e-mail: andant72@yahoo.com

${ }^{2}$ School of Public Health Addis Ababa University, P.O. Box: 9086, Fax- +251115517701 , Tel: +251911882912 , e-mail: aberakumie2@yahoo.com
} 
Cultural values towards sanitation facilities are key elements affecting the continued latrine utilization. Odour and fly problems are often quoted as deterrents to use latrine facilities $(5,12,24)$. The only available KAP study undertaken by Ministry of Health in Ethiopia in 1996/97 indicated that the major reasons for not using latrines were lack of superstructure, poor hygiene and poor maintenance of latrines (25). The availability of such infrastructure, however, is not worth unless the readiness to use is guaranteed. The same reference showed that $69 \%$ of respondents did not know what diseases are associated with drinking water and $53 \%$ of respondents were not aware at all that communicable diseases can be transmitted through human excreta. On the average latrine availability was about $10 \%$, of with self-reported utilization was $85 \%$. Locally published work in areas of latrine utilization in Ethiopia is not available. Generally, drinking water, sanitation, and hygiene related articles published in the pioneering Ethiopian Journal of Health Development is less than 5\% (26).

Given the provision of sanitation facilities were aggressively initiated in all parts of Ethiopia with interventions of health extension program since 2004, the impact of latrine utilization on the health of the community, particularly on under-five children, was not defined. This study was designed to show the benefits of latrine utilization and factors affecting utilization.

\section{Methods}

A cross-sectional study was carried out in the rural community of Hulet Ejju Enessie Wereda during September 2006. Wereda is a second hierarchy of local administrative unit which is equivalent to a district. The area is located in East Gojjam Zone of Amhara Regional State. It is located at about $370 \mathrm{Km}$ from Addis Ababa, $120 \mathrm{Km}$ from Bahir Dar, the regional capital and $210 \mathrm{Km}$ from DebreMarkos the zonal capital city. The Wereda had 6 urban Kebeles and 41 rural Kebeles. Kebele is the smallest administrative unit acting as a local government.

The Wereda was purposely selected with the view that it had $90 \%$ latrine coverage at the time this study was conducted. The sample size was calculated using single proportion formula with the assumption of $95 \%$ confidence interval (two-sided), an expected proportion (latrine utilization) of $90 \%$ in the Wereda, marginal error of $3 \%$, design effect of 2 and non-response rate of $10 \%$. Accordingly, a total of 838 study subjects were calculated for the study.

A stratified cluster sampling was applied to select the study subjects. The Wereda was stratified by climatic condition in to 'Kolla', 'Woyna Dega' and 'Dega' assuming that diarrhoeal diseases vary with climatic zone. In addition, stratification by ecology was considered in order to improve the efficiency of sampling. Ten Kebeles ( $25 \%$ of the rural Kebeles) were selected randomly and included in the study. Then 838 households with latrines were selected by using proportional allocation to the size of Kebeles. Eligible households were selected using a systematic sampling from the list of latrine owners registered by data collectors a week prior to the actual data collection date.

In order to avoid ambiguity of data collection, the following terms were operationally defined:

- Satisfactory Latrine utilization - households with functional latrines and the family disposed the faeces of under-five children in a latrine, no observable faeces in the compound, no observable fresh faeces on the inner side of the squatting hole and the presence of clear foot-path to the latrine is uncovered with grasses or other barriers of walking.

- Functional latrine - latrine with sub and superstructures and that provided services at the time of data collection even if the latrine required maintenance.

- Occurrence of childhood diarrhoea - the presence of diarrhoea (three and more loose or liquid stools per day) among under-five children in the house within two weeks period prior to survey, as reported by the caretaker of the child.

The pre-tested questionnaire was administered to a mother or guardian of the child. All study subjects were interviewed about latrine utilization and only those with both latrines and under-five children were interviewed about diarrhoeal diseases. Respondents were interviewed with a local language after ensuring the consistency and clarity of the English version.

A standardized and structured questionnaire was developed for the purpose of data quantitative collection. Ten health extension workers for data collection and two sanitarians for supervision were recruited before data collection. Field team members were trained for three days on the purpose, tasks and interviewing techniques with the provision of a field manual for data collection. Training for data collectors and supervisors were given for three days by preparing and using training manual that was purposely prepared for this study. Field supervisions and daily meetings during data collection were intense to ensure the quality of data collection.

All field questionnaires were first checked, and coded. Afterwards data were entered and cleaned using EPI ENFO software version 6.04. Analysis was conducted with SPSS software Version 11.0. A 10\% of entered data was re-entered to check the consistency of originally entered data by clerks. Descriptive statistics was performed using frequency distribution and percentages that were displayed using tables and figures. Bivaraiate and multivariate analyses using odds ratio with $95 \%$ CI were performed to find out an association between the dependent and independent variables in concern. The multivariate analysis was meant to explore the effect of 
latrine utilization on diarrhea by considering the hierarchical conceptual framework. In SPSS, "ENTER" method was used to assess the relative importance of the explanatory factors on diarrhea sickness. To avoid an excessive number of variables and unstable estimates in the subsequent model, only variables with p-value $<0.30$ were kept in the subsequent model analysis (27). The overall effect of the selected socioeconomic variables on childhood diarrhoeal disease was assessed in the first step of multivariate analysis. In the second step, the environmental variables were added, and their effect was assessed in the presence of socioeconomic variables that had $p$-value $<0.30$. In the third step, the effect of the selected behavioral factors was assessed in the presence of both socioeconomic and environmental factors that had p-value $<0.30$. Variables with $\mathrm{p}<0.05$ were considered for the condensed model.

The ethical approval was obtained from Medical Faculty of Addis Ababa University. Permission for data collection was obtained from respective local administrative bodies. Interview was carried out only with full consent of respondents. Confidentiality and privacy were maintained anonymously. Advising about home made therapy or appointment to bring children to health posts was made when children with diarrhoea were found during data collection.

\section{Results}

Socio-economic characteristics: A total number of 824 (98.3\%) households with latrines were included in the study. The majority, $(94.3 \%)$ of respondents was Orthodox Christians and almost all $(99.9 \%)$ belong to Amhara ethnicity. Most, 494 (60.0\%), households had a family size of $\leq 5$ persons, with a mean (SD) family size of $4.96( \pm 1.99)$. There were under-five children in 370 $(45 \%)$ households with a total of 447 children. One hundred two $(22.8 \%)$ under-five children were within 36-47 months age category and 234 (52.3\%) under-five children were females.

Six hundred nineteen (75.1\%) mothers and $512(71.4 \%)$ fathers were illiterate. Five hundred thirty three (64.7\%) households had children attending either primary or secondary school. Majority $(86.2 \%)$ of respondents were married. Seven hundred seventeen $(87.0 \%)$ households were predominantly headed by fathers. Majority of fathers $(98.3 \%)$ were engaged in farming. Fifty five percent mothers were housewives. Majority of the households $(89.3 \%)$ had at least one kind of domestic animals. Five hundred seventy five $(59.5 \%)$ households had 1-2 hectares of land, with a mean (SD) of 1.13 hectares $( \pm 0.57)$ that is used for agricultural purpose (Table 1).

Table1: Socio-economic characteristics of study subjects in the rural community of Hulet Ejju Enessie Woreda, September 2006

\begin{tabular}{|c|c|c|}
\hline Characteristics & Frequency & Percent \\
\hline \multicolumn{3}{|l|}{ Family Size $(n=824)$} \\
\hline$\leq 5$ & 494 & 60.0 \\
\hline$>5$ & 330 & 40.0 \\
\hline \multicolumn{3}{|c|}{ Educational status of mothers Size $(n=824)$} \\
\hline Illiterate & 619 & 75.1 \\
\hline Read and write & 140 & 17.0 \\
\hline Literate & 65 & 7.9 \\
\hline \multicolumn{3}{|c|}{ Educational status of the Father $(n=717)$} \\
\hline Illiterate & 512 & 71.4 \\
\hline Read and write & 140 & 19.5 \\
\hline Literate & 65 & 9.1 \\
\hline \multicolumn{3}{|c|}{ HHs with elementary or secondary school children } \\
\hline Yes & 533 & 64.7 \\
\hline No & 291 & 35.3 \\
\hline \multicolumn{3}{|l|}{ Marital status Size $(n=824)$} \\
\hline Married & 710 & 86.2 \\
\hline Unmarried & 14 & 1.7 \\
\hline Divorced/separated/Widowed & 100 & 12.1 \\
\hline \multicolumn{3}{|c|}{ Occupational status of mothers Size $(n=824)$} \\
\hline House wife & 454 & 55.1 \\
\hline Farmer & 349 & 42.4 \\
\hline Others & 21 & 2.6 \\
\hline \multicolumn{3}{|c|}{ Occupational status of Father $(n=717)$} \\
\hline Farmer & 705 & 98.3 \\
\hline Others & 12 & 1.7 \\
\hline \multicolumn{3}{|l|}{ Head of households Size (824) } \\
\hline Father & 717 & 87.0 \\
\hline Mother & 106 & 12.0 \\
\hline Others & 1 & 0.1 \\
\hline \multicolumn{3}{|c|}{ No. of under-five children in the household $(n=370)$} \\
\hline One & 305 & 82.4 \\
\hline Two to Three & 65 & 17.5 \\
\hline \multicolumn{3}{|c|}{ Water source for domestic purpose $(n=370)$} \\
\hline Protected & 161 & 43.5 \\
\hline Unprotected & 209 & 56.5 \\
\hline
\end{tabular}


Sanitation facilities: Almost all (99.8\%) types of available latrines were pit latrines. Majority $(63.5 \%)$ of latrines were constructed before 2 years and longer prior the study. The mean (SD) duration of having a latrine was 29.01 ( \pm 10.05$)$ months. Seven hundred fourteen $(86.7 \%)$ latrines were functional, of which 389 (54.5\%) latrines required maintenance. The remaining nonfunctional $(13.3 \%)$ latrines required rehabilitation works.
Only $6(0.8 \%)$ latrines had no superstructure. Majority $(93.4 \%)$ of latrine slabs were made of mainly mud, few cemented. About $66 \%$ of latrines had no cover on the squatting hole. About $57 \%$ of latrines were located $>6$ meters far away from houses. Four hundred ninety four $(69.2 \%)$ households with latrine had no any kind of hand washing facilities (Table 2).

Table 2: Distribution of respondents by environmental factors in the rural community of Hulet Ejju Enessie Woreda, September 2006

\begin{tabular}{|c|c|c|}
\hline Characteristics & Frequency & Percent \\
\hline \multicolumn{3}{|c|}{ Years since latrines constructed $(n=824)$} \\
\hline$<2$ yrs & 301 & 36.5 \\
\hline $2-3$ yrs & 345 & 41.9 \\
\hline$\geq 3$ yrs & 178 & 21.6 \\
\hline \multicolumn{3}{|l|}{ Functional latrines $(n=824)$} \\
\hline Yes & 714 & 86.7 \\
\hline No & 110 & 13.3 \\
\hline \multicolumn{3}{|l|}{ Status of latrines $(n=824)$} \\
\hline Need reconstruction & 110 & 13.3 \\
\hline Need no maintenance & 325 & 39.4 \\
\hline Need maintenance & 389 & 47.2 \\
\hline \multicolumn{3}{|c|}{ Parts of latrine requiring maintenance $(n=389)^{*}$} \\
\hline Superstructure & 231 & 59.4 \\
\hline Slab & 53 & 13.6 \\
\hline Roof & 200 & 51.4 \\
\hline Latrine pit & 17 & 4.4 \\
\hline \multicolumn{3}{|c|}{ Materials of latrine superstructure $(n=714)$} \\
\hline No superstructure & 6 & 0.8 \\
\hline Only with wood & 53 & 7.4 \\
\hline Wood plastered with mud & 652 & 91.3 \\
\hline Other & 3 & 0.4 \\
\hline \multicolumn{3}{|c|}{ Sealed or cemented latrine slabs $(n=714)$} \\
\hline Yes & 667 & 03.4 \\
\hline No & 47 & 6.6 \\
\hline \multicolumn{3}{|c|}{ Location of hand washing facilities from latrine $(n=714)$} \\
\hline Next to latrine & 176 & 24.6 \\
\hline Within walking distance & 15 & 2.1 \\
\hline Inside the house & 29 & 4.1 \\
\hline No facility & 494 & 69.2 \\
\hline \multicolumn{3}{|c|}{ Distance of latrine from the house $(n=714)$} \\
\hline$<6$ meters & 307 & 43.0 \\
\hline $6-10$ meters & 365 & 51.1 \\
\hline$\geq 10$ meters & 42 & 5.9 \\
\hline
\end{tabular}

* had multiple responses

Behavioral Factors: Most (76.1\%) of the respondents who had latrines explained that they were advised by extension health workers to construct latrines. Only 43 $(5.2 \%)$ respondents complained that they were imposed by other bodies like local administrators. Six hundred eighty nine $(96.5 \%)$ respondents explained that all family members of $\geq 5$ years old were using latrines. Reported utilization was $93 \%$ among respondents. There were observable faeces in the compound of $14.7 \%$ of the households. Six hundred fifty seven (92\%) households were observed with the presence of fresh faeces inside the pit of the latrine (an indication of utilization) and only
$13.6 \%$ of the foot-paths to the latrines were covered with grasses.

The extent of latrine utilization among 500 (60.7\%) households with latrines was satisfactory. Only 46 (12.4 $\%$ ) households responded that there were under-five children who used latrines. More than one-third of them began to use the latrine by the age of three years and $67 \%$ by the age of four years. One hundred and eight (38.9\%) households disposed their children's faeces improperly by disposing out of houses somewhere either in the backyard or in the nearby bush (Table 3). 
Table 3: Distribution of respondents by the behavioral factors in the rural community of Hulet Ejju Enessie Woreda, September 2006

\begin{tabular}{|c|c|c|}
\hline Characteristics & Frequency & Percent \\
\hline \multicolumn{3}{|l|}{ Latrine use by $\geq 5$ years old $(n=714)$} \\
\hline Males only & 20 & 2.8 \\
\hline Females only & 5 & 0.7 \\
\hline All family members & 689 & 95.5 \\
\hline \multicolumn{3}{|l|}{ Frequency of latrine use $(n=714)$} \\
\hline Rarely & 27 & 3.8 \\
\hline Mostly & 25 & 3.5 \\
\hline Always & 662 & 92.7 \\
\hline \multicolumn{3}{|c|}{ Observable faeces in the compound $(n=824)$} \\
\hline Yes & 121 & 14.7 \\
\hline No & 703 & 85.3 \\
\hline \multicolumn{3}{|c|}{ Presence of fresh faeces in the pit of latrine $(n=714)$} \\
\hline Yes & 657 & 92.0 \\
\hline No & 57 & 8.0 \\
\hline \multicolumn{3}{|c|}{ Latrine foot-path covered with grass $(n=714)$} \\
\hline Yes & 97 & 13.6 \\
\hline No & 617 & 86.4 \\
\hline \multicolumn{3}{|l|}{ Extent of latrine utilization $(n=824)$} \\
\hline Satisfactory & 500 & 60.7 \\
\hline Unsatisfactory & 324 & 39.3 \\
\hline \multicolumn{3}{|c|}{ Latrine use by under-five children $(n=370)$} \\
\hline Yes & 46 & 12.4 \\
\hline No & 324 & 87.6 \\
\hline \multicolumn{3}{|c|}{ Starting age of latrine use by $<5$ children $(n=46)$} \\
\hline At 2 years old & 1 & 2.2 \\
\hline At 3 years old & 14 & 30.3 \\
\hline At 4 years old & 31 & 67.4 \\
\hline \multicolumn{3}{|c|}{ Disposal means of faeces of children $(n=340)$} \\
\hline Pit latrine disposal & 224 & 65.9 \\
\hline Disposal by burying & 8 & 2.3 \\
\hline Disposing faeces out of houses & 108 & 31.8 \\
\hline
\end{tabular}

The reasons given by respondents for why under-five children did not use the latrines were: being just a child $(38.1 \%)$, large squatting hole $(17.4 \%)$, and floor was not safe to stand on $(15.5 \%)$. Majority of the respondents $(84.2 \%)$ reported to always use latrines because of their understanding about the danger of excreta to health. Among the reasons given by the respondents, nonfunctionality of latrines $(80 \%)$, and staying out for work $(7.3 \%)$ were the main reasons for not utilizing a latrine.

Predictors of latrine utilization: Selected variables that were significantly associated at the bivariate analysis were further examined in the logistic regression to see their relative effects on the extent of latrine utilization (Table 4). The presence of primary or secondary school children in a household increased latrine utilization [OR: 1.43, 95\% CI: (1.05-1.95)]. The extent of latrine utilization was about 5 times more satisfactory in the house that constructed latrine by learning from peer groups than being imposed by other bodies [OR: 5.38, 95\% CI :(1.53-18.94)]. Even though perceived reason of self initiation to construct latrine by the household had no significant association in the bivariate analysis, its association appeared in the multivariate analysis and the extent was 2 times more satisfactory than being imposed by other bodies to construct latrine [OR: 2.20, 95\%
CI:(1.01-4.76)]. The extent of latrine utilization was about 2 times more satisfactory in the households owning latrines for $\geq 2$ years than owning $<2$ years [OR: 1.82, 95\% CI: (1.33-2.51)]. The extent of latrine utilization were also less likely satisfactory both in 'Kolla' [OR: 0.47, 95\% CI: (0.29-0.74)] and 'Woyna Dega' [OR: 0.55, 95\% CI: (0.38-0.81)] than 'Dega' Zone.

Occurrence of childhood diarrhea: The two-week prevalence of diarrhea among under-five children was $6.5 \%$ prior the study period. From all variables entered in all steps of multivariate analysis, only duration of owning latrine by the household remained significant after adjusting socioeconomic, environmental and behavioral factors. Households owning latrines for $\geq 2$ years had a more likely protective effect (close to $70 \%$ ) of the occurrence of childhood diarrhoea [OR: 0.28 , 95\%CI: (0.12-0.66)] in final model of multivariate analysis than owning with in 2 years. Even though number of under-five children in a family, functional latrines, status of latrine, extent of latrine utilization, and observable faeces in the compound and in the neighborhoods showed significant association in the bivariate analysis, their significance disappeared in all steps of the multivariate analysis (Table 5). 
Table 4: Summary of logistic regression on predictors of the extent of latrine utilization in the rural community of Hulet Ejju Enessie Woreda, September 2006

\begin{tabular}{|c|c|c|}
\hline Characteristics & Crude OR (95\% CI) & Adjusted OR (95\% Cl) \\
\hline \multicolumn{3}{|c|}{ Households with elementary or secondary school children } \\
\hline Yes & $1.35(1.01-1.81)^{*}$ & $1.43(1.05-1.95)^{*}$ \\
\hline No & 1.00 & 1.00 \\
\hline \multicolumn{3}{|c|}{ Reasons given for latrine construction } \\
\hline Advise from health workers & $1.38(0.74-2.57)$ & $1.44(0.76-2.72)$ \\
\hline Self initiation & $1.93(0.91-4.01)$ & $2.20(1.01-4.76)$ \\
\hline Peer pressure & $4.57(1.34-15.55)^{\star *}$ & $5.38(1.53-18.94)^{\star *}$ \\
\hline Imposition from others & 1.00 & 1.00 \\
\hline \multicolumn{3}{|c|}{ Duration of owning latrine by household } \\
\hline$\geq 2$ years & $1.99(1.49-2.66)^{\star * *}$ & $1.82(1.33-2.51)^{\star * *}$ \\
\hline$<2$ years & 1.00 & 1.00 \\
\hline \multicolumn{3}{|l|}{ Climatic zone } \\
\hline 'Kolla' & $0.31(0.20-0.47)^{\star * *}$ & $0.47(0.29-0.74)^{\star *}$ \\
\hline 'Woyna Dega' & $0.50(0.35-0.72)^{\star * *}$ & $0.55(0.38-0.81)^{\star *}$ \\
\hline 'Dega' & 1.00 & 1.00 \\
\hline
\end{tabular}

Significant at $\mathrm{P}<0.05^{*} ; \mathrm{P}<0.005^{\star *} ; \mathrm{P}<0.001^{* * *}$

Table 5: Summary of logistic regression on the predictors of the occurrence of childhood diarrhea in the rural community of Hulet Ejju Enessie Woreda, September 2006

\begin{tabular}{|c|c|c|c|c|}
\hline \multirow[t]{2}{*}{ Characteristics } & \multirow{2}{*}{$\begin{array}{l}\text { Crude OR } \\
\text { (with } 95 \mathrm{Cl} \text { ) }\end{array}$} & \multicolumn{3}{|c|}{ Adjusted OR (with 95\% CI) } \\
\hline & & Model 1 & Model 2 & Final Model \\
\hline \multicolumn{5}{|l|}{$\begin{array}{l}\text { Model } 1 \text { (socio-economic } \\
\text { variables)\# }\end{array}$} \\
\hline$\leq 5$ members $/>5$ members ${ }^{*}$ & $0.51(0.23-1.14)$ & $0.69(0.26-1.88)$ & & \\
\hline \multicolumn{5}{|l|}{$\begin{array}{l}\text { Households with elementary or } \\
\text { secondary school children }\end{array}$} \\
\hline Yes/No* & $1.84(0.76-4.45)$ & $1.38(0.47-4.08)$ & & \\
\hline \multicolumn{4}{|l|}{ Occupational status of mother } & \\
\hline \multicolumn{5}{|l|}{ Number of $<5$ children in a house } \\
\hline \multicolumn{5}{|l|}{$\begin{array}{l}\text { Model } 2 \text { (socio-economic + } \\
\text { environmental variable)\# } \\
\text { Functional latrines }\end{array}$} \\
\hline Yes/No* & $0.37(0.15-0.89)^{\star *}$ & & $0.47(0.18-1.23)$ & $0.69(0.23-2.07)$ \\
\hline \multicolumn{5}{|l|}{ Status of latrine } \\
\hline Need/No need of reconstruction* & $2.71(1.13-6.52)^{\star *}$ & & $0.34(0.15-0.78)^{\star *}$ & $0.28(0.12-0.66)^{\star * *}$ \\
\hline \multicolumn{5}{|l|}{$\begin{array}{l}\text { Duration of owning latrine by } \\
\text { household }\end{array}$} \\
\hline$\geq 2 /<2 \mathrm{yrs}^{*}$ & $0.29(0.13-0.65)^{\star *}$ & & $0.34(0.15-0.78)^{\star *}$ & $0.28(0.12-0.66)^{\star * *}$ \\
\hline \multicolumn{5}{|l|}{$\begin{array}{l}\text { House shared with domestic } \\
\text { animals }\end{array}$} \\
\hline Yes/No* & $1.96(0.77-4.96)$ & & $1.58(0.60-4.18)$ & \\
\hline \multicolumn{5}{|l|}{ Climatic zone } \\
\hline 'Kola'/'Dega’* & $4.94(0.05-23.26)^{\star \star}$ & & $1.31(0.55-3.12)$ & \\
\hline \multicolumn{5}{|l|}{$\begin{array}{l}\text { Model } 3 \text { (socio-economic + env. + } \\
\text { behavioral variables)\# } \\
\text { Extent of latrine utilization }\end{array}$} \\
\hline Satisfactory/unsatisfactory* & $0.38(0.17-0.87)^{\star \star}$ & & & $0.63(0.22-1.81)$ \\
\hline \multicolumn{5}{|l|}{$\begin{array}{l}\text { Observable faeces in the } \\
\text { Compound }\end{array}$} \\
\hline Yes/NO* & $2.61(1.15-5.94)^{\star *}$ & & & $1.40(0.48-4.09)$ \\
\hline \multicolumn{5}{|l|}{$\begin{array}{l}\text { Observable faeces in the } \\
\text { neighborhood yard }\end{array}$} \\
\hline Yes/No* & $2.47(1.06-5.75)^{\star *}$ & & & $1.51(0.58-3.96)$ \\
\hline \multicolumn{5}{|l|}{ Latrine use by under-five children } \\
\hline Yes/No* & $0.24(0.03-1.84)$ & & & $0.23(0.03-1.88)$ \\
\hline \multicolumn{5}{|l|}{ Per capita water consumption } \\
\hline$<10$ lits/>10 lits* & $2.55(0.86-7.54)$ & & & $2.72(0.87-8.46)$ \\
\hline \multicolumn{5}{|l|}{ Supplementary feeding practices } \\
\hline Bottle/cup feeding ${ }^{*}$ & $0.43(0.01-1.87)$ & & & $0.43(0.09-2.05)$ \\
\hline \multicolumn{5}{|l|}{ Vit. A supplemented children } \\
\hline Yes/No* & $3.48(0.46-26-29)$ & & & $3.25(0.40-27.26)$ \\
\hline
\end{tabular}




\section{Discussion}

The findings of this study revealed that self-reported usage of latrine by adults was about $97 \%$ which is nearest to the report in Lesotho (99\%) (28). However, the use of latrines by children was not encouraging. Few children began to use the latrine at the age of 3 years in this study. In Kenya although children began to use the latrine as early as 2 years, most of them start at the age of 5 which is consistent with the present study. The methods of handling of faeces of under-five children varied among respondents: $65.9 \%$ disposing faeces in the latrine, $2.3 \%$ burying while $31.8 \%$ disposing around the house either in the bush or in the garden. This behavior is entirely unacceptable practice of handling faeces. The use of latrine for safe disposal of children faeces in the present study was better when compared with the reports in Kenya (53\%) (29), Lesotho (50\%) (28) and Philippines $(39 \%)(30)$. However, disposing faeces out of the house was higher than the reported in Kenya (12\%) (29).

The presence of primary or secondary school children in the house was associated with the extent of latrine utilization. The fact that students were more exposed to hygiene information in the school environment, their presence positively favored the persuasion of latrine utilization in the home environment. The Wereda Health Officer reported (personal communication) that health extension program was closely linked to the promotion of school health, which was an additional opportunity for students to learn healthy lifestyles. Maternal education was not associated with the extent of latrine utilization, although a more likely increase of latrine utilization was observed among literate mothers than illiterate mothers. Mother's education was known to encourage latrine use (31) and protect a child from diarrhea (32-33). The Ethiopian DHS has also indicated variations in the prevalence of diarrhea by education and presence of improved latrine (12).

Peer pressure was also associated with the extent of latrine utilization. This is due to the fact that people can learn to accept, adopt and utilize latrine facilities easily by following role model individuals and observing model latrine facilities than mere advice and enforcement. The health extension program in Ethiopia is known for the provision and promotion of role models, which serve being a springboard for public health education. Duration of owning latrine by household was also associated with the extent of latrine utilization. The process of behavioral changes towards appreciating the advantages of latrine facilities require some threshold time that may require for the modification of individual's behavior. The extent of latrine utilization was also significantly different by climatic zones. Residents in "Kola" were less likely to use latrines than residents in other climate zones. The wide spread open defecation practice in Kola agroecology might be linked to fear of odour and flies that are inherent problems of traditional pit latrines. There is also a taboo among respondents that faecal matter under sunlight dries up quickly and becomes harmless in the open space in such hot climate as "Kola".

Knowledge on the danger of excreta and the perceived advantage of using latrines, particularly for girls and women in a community where defecation during the day time is shame, were key factors that facilitated latrine use by the household members (34). Major reasons that deter latrine use by the households were non-functional latrines, staying out for farming, and the absences of superstructure. These are about similar to the survey conducted in 1997 (25). Mother's education (Kenya), latrine design, accessibility, and maintenance (Nepal), user being women (India) were important determinants for latrine use (34).

In the present study, the two-week prevalence rate of under-five diarrhea was $6.5 \%$, which is much below the 2005 Ethiopian DHS report (18\%) (12). The difference in sample size, time of the study, and the difference in the background of study areas might explain these variations. Diarrhea morbidity rates were found to be highest $(65.5 \%)$ in children with 6-23 months age compared to other age groups, which is consistent with the 2005 EDHS (57.6\%) and other studies (35-38). The occurrences of childhood diarrhoea were not significantly associated with family size, annual family income, educational status of parents and children, and occupation of mothers. Their contribution to the occurrence of childhood diarrhoea was small in comparison to the environmental and behavioral factors. Studies in Nepal (28) showed that an apparent increased risk of diarrhoea in children of literate mothers, probably due to improved recognition of the condition in the child, seemed to be consistent with this study. The occurrence of childhood diarrhoea did not differ by occupation of mothers, which is inconsistent with other findings (39).

The occurrence of childhood diarrhoea was also associated with the extent of latrine utilization, presence of faeces in the backyard as well as in the neighborhood's yard in the bivariate analysis. A study in Ghana indicated similar findings (40). Open field defecation is a primary practice to easily acquire diarrhea related infections. The only factor that contributed to the increased risk of diarrhea among children in the multivariate logistics regression analysis was the duration of owning latrine for a longer period by households. This indicates that a behavioral change towards sanitation is not a matter of an overnight goal. It requires long-term sustained effort of health promotion that aims the utilization of latrine facilities.

In conclusion, this study showed encouraging practice in latrine use. The presence a school children in a household, duration of owning a latrine, peer pressure, and self initiation to owe latrine due to the promotional activity of health extension workers were the major factors affecting utilization of latrines. The mere latrine 
utilization did not impact the occurrence of childhood diarrhoeal diseases, while the duration of utilization was a strong predictor to bring visible changes in future. Strengthening the link between sustained utilization and continued hygiene education should remain prudent. The involvement of health extension workers in data collection in a program they are involved might have biased the results, specifically the occurrence of diarrhea, despite the study involved intensive daily supervision during data collection. In addition, a one-time survey undefined seasonal variability were limitations of this study to demonstrate strong evidence for the impact of latrine utilization on diarrhea. Availability of literature addressing our research questions was also a limiting factor to discuss our findings.

\section{Acknowledgements}

We would like to acknowledge the School of Public Health of the Addis Ababa University for financing this study. Appreciation also goes to all staffs of East Gojjam Zonal Health Department, and health extension workers for their assistance during data collection. Mothers and care takers of children are greatly thanked for their time to participate in this study.

\section{References}

1. Grosvenor Press International LTD. Developing world health: Water supply and sanitation in developing countries; 1986.

2. World Health Organization. World Water Day 2001: Sanitation: Controlling Problems at Source. Available from: URL: http://www.worldwaterday.org/wwday/2001/themati c/control.html.

3. World Health Organization. PHAST step by step Guide: Participatory approach for the control of diarrhoeal diseases; 2000.

4. World Health Organization. Healthy villages: A guide for communities and communities health workers. Geneva; 2002.

5. Mc Convile J. Field engineering in the developing world: How to Promote the Use of Latrines in Developing Countries; 2003. Available from: URL: www.cee.mtu.edu/peacecorps.

6. Jabu G. Assessment and comparison of microbial quality of drinking water in Chikwawa; 2006. Available from: URL: http://www.poly.ac.mw/centres/washted/images/pdfs irish.post-graduate.conference.paper.pdf.

7. World Bank. Water supply and sanitation. Hygiene and sanitation promotion: why promote sanitation? 2002.

8. United Nations Environment Program, United Nations Children's Fund, World Health Organization. Children in the new millennium: Environmental impact on health; 2002.

9. World Health Organization, UNICEF. African Regional water supply and sanitation assessment Report; 2000. Available from: URLL http://www.who.int/water sanitation health/monitor ing/globalassess/en/.

10. World Health Organization, UNICEF. Meeting the MDG drinking water and Sanitation: a mid-term Assessment of Progress; 2002. Available from: URL:http://www.who.int/water_sanitation_health/m onitoring/jmp04.pdf.

11. World Health Organization, UNICEF. A Snapshot of Sanitation in Africa A special tabulation for Africa San. Based on preliminary data from the WHO/UNICEF. Joint Monitoring Program for Water Supply and Sanitation. Africa San: Second African Conference on Sanitation and Hygiene Durban, South Africa; February 18-20,2008. Available from: URL:

http://www.who.int/water_sanitation health/monitor ing/africasan.pdf2008.

12. Central Statistical Agency Ethiopia, ORC Macro USA. Ethiopia Demographic and Health Survey 2005. Addis Ababa; 2006.

13. United Nations. The Millennium Development Goals Report 2005. United Nations report. New York; 2005.

14. Esrey SA, Potash JB, Roberts L, Shiff C. Effects of improved water supply and sanitation on ascariasis, diarrhoea, dracunculiasis, hookworm infection, schistosomiasis, and trachoma. Bulletin of the WHO 1991;69(5):609-21.

15. Charles P, Lulseged S, Kitsela T. Child hood diarrhoea. In: Berhane Y, Haile Mariam D, Kloos H, editors. Epidemiology and Ecology of Health and Disease in Ethiopia. Addis Ababa: Shama Books; 2006.

16. Mulugeta T. Socio-economic, environmental, and behavioral factors associated with the occurrence of diarroeal disease among under-five children, Meskanena-Mareko Woreda, Southern Ethiopia [MPH dissertation]: Addis Ababa University; 2003.

17. Eshete WB. A stepwise regression analysis on under-five diarrhoael morbidity prevalence in Nekemte town, western Ethiopia: maternal care giving and hygiene behavioral determinants. East Afr J Public Health 2008;5(3):193-8.

18. World Health Organization. Prevention of diarrhea (unit 8) - Medical Education: Teaching Medical Students about diarrhoeal diseases; 1993.CDD/SER/93.3. Available from: URL: http://www.who.int.

19. Fewtrell L, Kaufmann R, Kay D, Enanoria W, Haller L, Colford JJ. Water, sanitation, and hygiene interventions to reduce diarrhea in less developed countries: a systematic review and meta-analysis Lancet Infectious Diseases 2005;5(1):42-52.

20. Esrey S, Feachem R, Hughes J. Intervention for the control of diarrhea diseases among young children: improving water supplies and excreta disposal facilities. Bulletin of the WHO 1985;63:757-72.

21. Fewtrell L, Colford JJ. Water, sanitation, and hygiene in developing countries: interventions and

Ethiop. J. Health Dev. 2010;24(2) 
doiarrihoea: a review. Water Sci Technol 2005;52(8):133-42.

22. Van Derslice J, Briscoe J. Environmental interventions in developing countries: interactions and their implications. Am $\mathrm{J}$ Epidemiol $1995 ; 15 ; 141(2): 135-44$.

23. Mertens TE, Fernando MA, Cousens SN, Kirkwood BR, Marshall TF, Feachem RG. Childhood diarrhoea in Sri Lanka: a case-control study of the impact of improved water sources. Trop Med Parasitol 1990;41(1):98-104.

24. Kumie A, Ali A. An overview of environmental health status in Ethiopia with particular emphasis to its organization; A literature survey of drinking water and sanitation. Ethiop $J$ Health Dev 2005;19(2):89-101.

25. Ministry of Health Ethiopia, Environmental Health Department. KAP study on water supply, environmental sanitation and hygienic practice in the selected Woredas of Ethiopia 1997.

26. HailevMariam D, Haidar J. A brief overview of issues addressed by EJHD publications (including index). Ethiop $J$ Health Dev 2009;23(Special Issue):187-223.

27. Victoria C, Huttly S, Fuchs S, Olinto M. The role of conceptual frameworks in epidemiological analysis: A hierarchical approach. Int J Epid1997;26(1):224-7.

28. Daniels D, Counsens S, Makoae L, Feachem R. A case control study of improved sanitation on diarrhoea morbidity in Lesotho. Bulletin of the WHO 1990;68(4): 455-63.

29. Moi University FoHS. Field Attachment: A report on Kapuonja Community and Chulaimbo provincial rural health training center in Maseno division, Kisumu district: htlm Document; 2006

30. Van Deslice J, Popkins B, Briscoe J. Drinking water quality, sanitation and breast feeding: their interactive effects on infant health. Bulletin of the WHO 1994;72(4):587-601.

31. Siziya S, Muula A, Rudatsikira E. Diarrhoea and acute respiratory infections prevalence and risk factors among under-five children in Iraq in 2000. Riv Ital Pediatr 2009;35(1):8-13.
32. Manun'ebo M, Haggerty P, Kalengaie M, Ashworth A, Kirkwood B. Influence of demographic, socioeconomic and environmental variables on childhood diarrhoea in a rural area of Zaire. Trop Med Hyg 1994;97(1):31-8.

33. Swami H, Thakur J, Gupta M, SP B. Improving environmental conditions of a slum in Chandigarh by an awareness campaign. J Environ Sci Eng 2004;46(3):252-6.

34. IRC International Water and Sanitation Centre. INCO : International Scientific Cooperation Projects Final Report (1998-2002): Sustaining changes in hygiene behavior. Available from: URL: http://www.irc.nl/index.php/content/view/full/28820 $\underline{02}$.

35. World Health Organization. Indicators to improve children's Environmental Health: Diarrhoeal diseases. Geneva; WHJO, 2003.

36. Snyder J, Merson M. The magnitude of the global problem of acute diarrhoeal diseases: a review of active surveillance data. Bulletin of the WHO 1982;69(4):605-13.

37. Bern C, Mertines J, deZonysa I, Glass R. The magnitude of the global problem of diarrhoeal diseases; a ten year update. Bulletin of the WHO 1992;70(6): 705-14.

38. Nepal NMIS Cycle 3: Diarrhoea, Water and Sanitation. Results from Nepal on diarrhoea and sanitation, 1996. Available from: URL: http://www.npc.gov.np/unicef/nmis/3rd_cycle/execu tive summary.htm.

39. Saran M, Gaur S. Epidemiologic correlates of diarrhea in a slum community in Varanasi. Indian Journal of Pediatrics 1981;48(393):441-6.

40. Boadi KO, Kuitunen M. Childhood diarrhoea morbidity in the Accra Metropolitan Area, Ghana: Socio-economic, environmental and behavioral risk determinants in Developing Countries/URL 2005;March:31-44. 